\title{
Growth Inhibitory Activity of Acronychia acidula F. Muell. Fruit Extracts Towards Malodour-forming Bacteria
}

\author{
Mitchell Henry Wright ${ }^{1}$, Aiden Wood ${ }^{2}$, Anthony Carlson Greene ${ }^{2}$, Ian Edwin Cock ${ }^{1,2,3, *}$ \\ 'Leviathan Biosciences, Brisbane, Queensland, AUSTRALIA. \\ ${ }^{2}$ School of Environment and Science, Griffith University, Brisbane, Queensland, AUSTRALIA. \\ 'Environmental Futures Research Institute, Nathan Campus, Griffith University, Brisbane, Queensland, AUSTRALIA.
}

\begin{abstract}
Introduction: Acronychia acidula F. Muell. (lemon aspen, pigeon berry) has been previously recognized for its antimicrobial properties against a broad panel of pathogenic bacteria. This study assessed the effectiveness of $A$. acidula as an inhibitory agent against bacteria associated with malodour formation. Methodology: $A$. acidula fruit extracts were prepared using methanol or water as the extraction solvent. Growth inhibition and minimal inhibitory concentrations were determined against $C$. jeikeium, $P$. acnes and $B$. linens through disc diffusion assays. MIC values were quantified to evaluate their efficacies as antimicrobials. Toxicity of each extract was determined using the Artemia franciscana nauplii bioassay. Results: A. acidula aqueous fruit extracts inhibited the growth of $B$. linens $(\mathrm{MIC}=$ $1258 \mu \mathrm{g} / \mathrm{mL})$, C. jeikeium $(\mathrm{MIC}=1630 \mu \mathrm{g} / \mathrm{mL})$ and $P$. acnes $(\mathrm{MIC}=1455$ $\mu \mathrm{g} / \mathrm{mL}$ ) in the disc diffusion assay. Similarly, the methanolic fruit extracts inhibited the growth of $B$. linens ( $\mathrm{MIC}=2608 \mu \mathrm{g} / \mathrm{mL}$ ) and $C$. jeikeium (MIC $=3044 \mu \mathrm{g} / \mathrm{mL}$ ), although no growth inhibition of $P$. acnes was observed. Both aqueous and methanolic $A$. acidula extracts were nontoxic towards Artemia nauplii ( $\mathrm{LC}_{50}$ values of $1872 \mu \mathrm{g} / \mathrm{mL}$ and $\left.1500 \mu \mathrm{g} / \mathrm{mL}\right)$. Conclusion:
\end{abstract}

A. acidula fruit extracts were non-toxic and also displayed moderate growth inhibitory bioactivity against $B$. linens, $C$. jeikeium and $P$. acnes, highlighting their potential as additives to deodorants.

Key words: Axilliary odour, Corynebacterium, Deodorant, Anti-perspirant, Foot odour, Lemon aspen

\section{Correspondence:}

Dr. Ian Edwin Cock

${ }^{1}$ Leviathan Biosciences, Brisbane, Queensland, AUSTRALIA.

${ }^{2}$ School of Environment and Science, Griffith University, 170 Kessels Rd, Nathan, Brisbane, Queensland-4111, AUSTRALIA.

${ }^{3}$ Environmental Futures Research Institute, Griffith University, 170 Kessels Rd, Nathan, Brisbane, Queensland-4111, AUSTRALIA.

Phone no: +61737357637

E-mail: i.cock@griffith.edu.au

DOI: $10.5530 /$ pc.2020.2.18

\section{INTRODUCTION}

Antiperspirants and deodorants comprise one of the largest product categories within the cosmetic industry. Indeed, it is estimated that they are regularly used by more than $90 \%$ of adults in the United States. ${ }^{1}$ While these products are commonly sold as a combined product, there is a distinct difference between these two methods of malodour mitigation. Deodorants are formulated to prevent the formation of odour by inhibiting the growth of the odour producing microflora, whereas antiperspirants are designed to decrease the production of perspiration, thereby inhibiting the conversion of sweat components into volatile compounds. Although body odour is a natural occurrence that occurs through bacterial decomposition of fats and other bodily secretions, its negative societal connotations have necessitated the production and commercialisation of products aimed at blocking odour production. These are sold as aerosols, roll-ons, as a powdered form or as a gel and these products combined generate over $\$ 1$ billion annually in the US alone. ${ }^{2}$

Secretion of sweat and other wastes serve as nutrient sources for bacteria present in the axillary and plantar regions of the body. Malodour of the axillary region of the body is produced by three prevailing bacterial genera; Staphylococcus, Propionibacterium and Corynebacterium..$^{3-5}$ This occurs through the enzymatic breakdown of sulfanylalkanols, shortbranched chain fatty acids and steroidal compounds, with malodourous volatiles produced as a result. Whilst Staphylococcus spp. and Propionibacterium spp. play a lesser role, Corynebacterium spp. are widely considered the primary contributors of axillary odour. Similarly, these same processes that are also responsible for odour in the plantar region of the body. In contrast, the main contributory genera to foot odour are Brevibacterium and Propionibacterium. ${ }^{6}$

Deodorants and antiperspirants are formulated to minimize growth of odour forming bacteria. However, there are concerns that some of these products may be hazardous to human health. For example, aluminium zirconium was used an additive in aerosolized antiperspirants since the 1950s, although it was subsequently banned by the Food and Drug Administration (FDA) in 1977 due to significant concerns surrounding its safety. ${ }^{7}$ However, similar aluminium salts are still included in antiperspirant preparations in many parts of the world. More recently, triclosan (an antimicrobial compound used in deodorants) has been linked to dermal irritation and may trigger allergies in some people. ${ }^{8}$ Although rigorous testing is performed today, there are still concerns surrounding the application of chemically-based deodorants or antiperspirants to the skin. Investigating biological alternatives to circumvent such concerns offers a potential alternative to current formulations. The antibacterial properties of many plants have been long recognized by many cultures and may serve as alternatives to chemically formulated deodorants and antiperspirants.

Acronychia acidula F. Muell. (commonly known lemon aspen, lemon wood, pigeon berry or hard aspen) is a fruit-bearing tree that is native to the Queensland region of Australia. It is found in the north-eastern and central regions of that state., ${ }^{9,10}$ Leaves are glossy green and bladed, spanning an average $15 \mathrm{~cm}$ long by $8 \mathrm{~cm}$ wide with round, yellow-white berries (Figure 1). The tree can grow upwards of $15 \mathrm{~m}$ high. Australian Aborigines consumed A. acidula and the fruits were favoured by early settlers who used it as a component in drinks. ${ }^{11}$ The fruit is known for its high antioxidant capacity, exceeding that of blueberries and citrus fruits. ${ }^{10}$ Whilst there have been limited scientific studies into the antibacterial properties of $A$. acidula, it is likely the high antioxidant capacity may prevent the growth of malodour causing bacteria. Indeed, previous studies using high antioxidant plants within our laboratory have highlighted the inhibition of malodour forming bacteria by Terminalia and 
Syzygium species. ${ }^{4,5,12}$ Furthermore, $A$. acidula has been shown to have activity against other pathogens, including various autoimmune bacteria, as well as the zoonotic bacterium Bacillus anthracis. ${ }^{13,14}$ For this work, A. acidula fruit extracts were prepared and assessed against a panel of malodour forming bacteria to determine their antimicrobial potential. Phytochemical compounds were identified by LC-MS fingerprinting and potential bioactive compounds were highlighted.

\section{MATERIALS AND METHODS}

\section{Plant collection and extraction}

A. acidula fruit was provided by Taste of Australia (http://www.bushfoodshop.com.au/brands/Taste-Australia.html). The fruit were dried using a Suinbeam food dehydrator and stored at $-30^{\circ} \mathrm{C}$ until use. Extracts were prepared as previously described. ${ }^{15,16}$ Briefly, stored fruit materials were thawed and ground into a coarse powder and 1 gram of the ground fruit was weighed into tubes in triplicate, followed by the addition of 50 $\mathrm{mL}$ of water or methanol (Ajax Fine Chemicals, Australia; AR grade). The fruit material was extracted in each solvent for $24 \mathrm{hr}$ at $4^{\circ} \mathrm{C}$ with gentle shaking. The extracts were filtered using Whatman No. 54 filter paper under vacuum, followed by drying in an Eppendorf concentrator

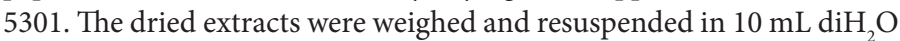
(containing 1\% DMSO).

\section{Qualitative phytochemical studies}

Phytochemical analyses of the extracts for the presence of anthraquinones, alkaloids, saponins, phenolic compounds, cardiac glycosides, phytosterols, flavonoids, tannins and triterpenoids were conducted as previously described. ${ }^{17,18}$

\section{Antioxidant capacity}

The antioxidant capacities of the fruit extracts were assessed using the DPPH free radical scavenging procedure with modifications. ${ }^{19,20}$ Briefly, ascorbic acid references (0-25 $\mu \mathrm{g})$ were utilised and the absorbances determined at $515 \mathrm{~nm}$. All assays were run alongside controls on each plate and all tests were performed in triplicate. The antioxidant capacity (based on the DPPH free radical scavenging ability) was calculated for each extract and expressed as $\mu$ g ascorbic acid equivalents per gram of the original plant material extracted.

\section{Test bacterial strains}

Media and components were supplied by Oxoid Ltd., Australia. Reference strains of Brevibacterium linens (ATCC9172), Corynebacterium

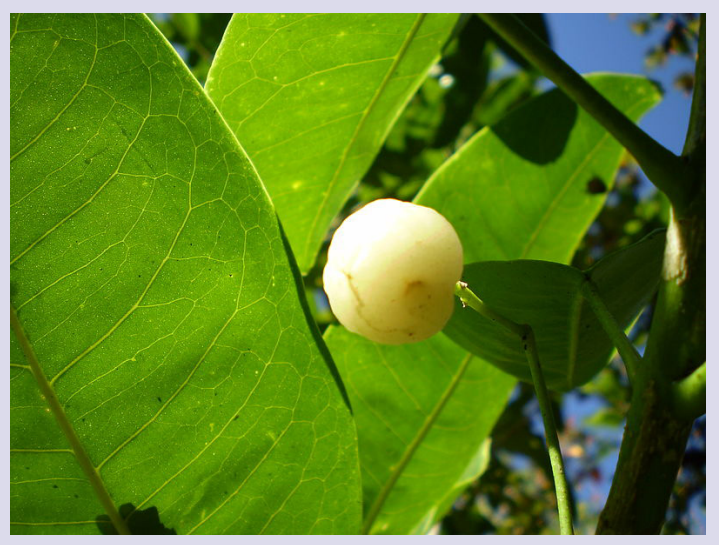

Figure 1: Leave and fruit of Acronychia acidula (lemon aspen). jeikeium (ATCC43734) and Propionibacterium acnes (ATCC6919) were purchased from American Type Culture Collection, USA. To culture the bacteria, $B$. linens was inoculated into separate flasks of nutrient broth and grown aerobically at $37^{\circ} \mathrm{C}$ for $24 \mathrm{hr}$. Cultures of C. jeikeium were grown and maintained in nutrient broth supplemented with 300 $\mu \mathrm{L}$ Tween $80 / \mathrm{L}$ of broth at $37^{\circ} \mathrm{C}$ for $24 \mathrm{hr}$. P. acnes was cultured using a thioglycolate liquid media under induced anaerobic conditions through the use of anaerobic jars and AnaeroGen ${ }^{\text {max }} 3.5 \mathrm{~L}$ atmospheric generation systems (Thermo Scientific). Incubation was at $37^{\circ} \mathrm{C}$ for $72 \mathrm{hr}$. All stock cultures were subcultured and maintained in liquid media at $4^{\circ} \mathrm{C}$. Subculture purity was periodically confirmed as previously described. ${ }^{21,22}$

\section{Evaluation of antibacterial activity}

The antibacterial activity of the $A$. acidula fruit extracts against $B$. linens and $C$. jeikeium was determined using a modified disc diffusion assay. ${ }^{23}$ Briefly, $100 \mu \mathrm{L}$ of B. linens, C. jeikeium or P. acnes was grown aerobically in $10 \mathrm{~mL}$ of fresh nutrient broth until they reached a count of $\sim 10^{8}$ cells/mL. Aliquots $(100 \mu \mathrm{L})$ of the bacterial suspensions were spread onto plates and each extract was tested for antibacterial activity using 6 $\mathrm{mm}$ sterilised filter paper discs. Discs were infused with $10 \mu \mathrm{L}$ of either extract, allowed to dry and placed onto the inoculated plates and kept at $4^{\circ} \mathrm{C}$ for $2 \mathrm{hr}$ before incubation at $37^{\circ} \mathrm{C}$ for $24 \mathrm{hr}$. Plates spread with $P$. acnes cultures were kept at $4^{\circ} \mathrm{C}$ for $2 \mathrm{hr}$ before incubation under induced anaerobic conditions at $37^{\circ} \mathrm{C}$ for $72 \mathrm{hr}$. Each test was performed three times, each with internal triplicates $(n=9)$. Mean values $( \pm$ SEM) are reported in this study. Standard discs of vancomycin $(5 \mu \mathrm{g})$ were prepared and used as positive controls to compare antibacterial activity. Filter discs infused with $10 \mu \mathrm{L}$ of distilled water were used as a negative control.

\section{Disc diffusion MIC assay}

The minimum inhibitory concentrations (MIC) of both extracts were evaluated by disc diffusion assay as previously described ${ }^{24}$ Briefly, the $A$. acidula aqueous and methanolic fruit extracts were diluted in deionised water and tested across a range of concentrations. Discs were impregnated with $10 \mu \mathrm{L}$ of the extract dilutions, allowed to dry and placed onto treated plates. The assay was achieved as outlined above and graphs of inhibitory zones versus concentration were plotted. MIC values were determined using linear regression.

\section{Toxicity screening}

\section{Reference toxin for toxicity screening}

Potassium dichromate $\left(\mathrm{K}_{2} \mathrm{Cr}_{2} \mathrm{O}_{7}\right)$ (AR grade, Chem-Supply, Australia) was prepared in deionised water $(4 \mathrm{mg} / \mathrm{mL})$ and serially diluted in artificial seawater for use in the Artemia franciscana nauplii bioassay.

\section{Artemia franciscana nauplii toxicity screening}

Toxicity was assessed using an adapted Artemia franciscana nauplii lethality assay. ${ }^{25}$ Briefly, $400 \mu \mathrm{L}$ of seawater containing $\sim 43$ (mean $42.7, n=$ 125 , SD 14.7) A. franciscana nauplii were added to wells of a 48 well plate and immediately used in the bioassay. Volumes of $400 \mu \mathrm{L}$ of the reference toxin or the diluted plant extracts were transferred to the wells and incubated at $25 \pm 1^{\circ} \mathrm{C}$ under artificial light (1000 Lux). For each plate, $400 \mu \mathrm{L}$ seawater negative controls were run in triplicate. The wells were assessed at regular intervals and the number of dead counted. The nauplii were deemed dead if no movement of the appendages was observed within $10 \mathrm{sec}$. After $24 \mathrm{hr}$, all nauplii were sacrificed and counted to determine the total $\%$ mortality per well. The $\mathrm{LC}_{50}$ ( $95 \%$ confidence limits) for each treatment were calculated using probit analysis. 


\section{HPLC-MS QTOF metabolomics fingerprinting}

Chromatographic separations were performed as previously described. ${ }^{26}$ Briefly, $2 \mu \mathrm{L}$ of each sample was injected onto an Agilent 1290 HPLC system fitted with a Zorbax Eclipse plus $\mathrm{C}_{18}$ column $(2.1$ x $100 \mathrm{~mm}, 1.8 \mu \mathrm{m}$ particle size). The mobile phases consisted of (A) ultrapure water and (B) 95:5 acetonitrile/water at a flow rate of $0.7 \mathrm{~mL} / \mathrm{min}$. Both mobile phases were modified with $0.1 \%(\mathrm{v} / \mathrm{v})$ glacial acetic acid for mass spectrometry analysis in positive mode and with $5 \mathrm{mM}$ ammonium acetate for analysis in negative mode. The chromatographic conditions utilised for the study consisted of the first 5 min run isocratically at $5 \% \mathrm{~B}$, a gradient of (B) from $5 \%$ to $100 \%$ was applied from $5 \mathrm{~min}$ to $30 \mathrm{~min}$, followed by 3 min isocratically at $100 \%$. Mass spectrometry analysis was performed on an Agilent 6530 quadrupole time-of-flight spectrometer fitted with a Jetstream electrospray ionisation source in positive mode. Data was analysed using the Masshunter Qualitative analysis software package (Agilent Technologies). Blanks using each of the solvent extraction systems were assessed using the Find by Molecular Feature algorithm in the software package to generate a compound list of molecules with abundances greater than 10,000 counts. This was then used as an exclusion list to eliminate background contaminant compounds from the analysis of the extracts. Each extract was then analysed using the same parameters using the 'Find by Molecular Feature' function to generate a putative list of compounds in the extracts. Compound lists were then screened against three accurate mass databases; a database of known plant compounds of therapeutic importance generated specifically for this study (800 compounds); the Metlin metabolomics database (24,768 compounds); and the Forensic Toxicology Database by Agilent Technologies (7,509 compounds). Empirical formula for unidentified compounds was determined using the Find Formula function in the software package.

\section{Statistical analyses}

Data is expressed as the mean \pm SEM of at least three independent experiments unless otherwise states.

\section{RESULTS}

\section{Liquid extraction yields and qualitative phytochemical screening}

Extraction of $1 \mathrm{~g}$ of the water and methanolic A. acidula fruit materials yielded dried plant extracts of $162 \mathrm{mg}$ (aqueous fruit extract) to $360 \mathrm{mg}$ (methanolic fruit extract) (Table 1). The dried extracts were resuspended in $10 \mathrm{~mL}$ of deionised water (containing $1 \% \mathrm{DMSO}$ ) resulting in the extract concentrations shown in Table 1.

Phytochemical analyses revealed high levels of phenolics, flavonoids, as well as moderate levels of triterpenes and low levels of cardiac glycosides (Table 1). Saponins were also detected in the aqueous extract, but not in the methanolic extract. Antioxidant capacities for the plant extracts were $16.2 \mathrm{mg}$ (aqueous fruit extract) and $36 \mathrm{mg}$ (methanolic fruit extract) ascorbic acid equivalence per gram of dried plant material extracted.

\section{Antimicrobial activity}

To determine the ability of the crude plant extracts to inhibit the growth of B. linens, $C$. jeikeium and $P$. acnes, aliquots $(10 \mu \mathrm{L})$ of each extract were screened using a disc diffusion assay. Bacterial growth was strongly inhibited by both the methanolic and aqueous extracts, against all three strains, except for the methanolic fruit extract and P. acnes (Figure 2). The aqueous fruit extract was more potent than the methanolic extract across all bacteria tested, with inhibition zones of $8.3 \pm 0.3 \mathrm{~mm}$ (B. linens), $8.0 \pm 0.6 \mathrm{~mm}$ (C. jeikeium) and $7.7 \pm 0.3 \mathrm{~mm}$ (P. acnes).

The antimicrobial efficacy was further quantified by determining the
MIC values (Table 2). Several of the extracts were effective at inhibiting microbial growth, with MIC values against $A$. acidula $<1000 \mu \mathrm{g} / \mathrm{mL}(<10$ $\mu \mathrm{g}$ impregnated in the disc). The $A$. acidula aqueous extracts were more potent than the methanolic counterparts, with MIC values of 1258-1630 $\mu \mathrm{g} / \mathrm{mL}(\sim 12-16 \mu \mathrm{g}$ impregnated in the disc). Although less potent, the methanolic fruit extracts were also good anti-A. acidula agents (MIC values $1500-3000 \mu \mathrm{g} / \mathrm{mL}$ ).

\section{Quantification of toxicity}

Extracts were initially screened at $2000 \mu \mathrm{g} / \mathrm{mL}$ in the assay (Figure 3). The reference potassium dichromate toxin $(1000 \mu \mathrm{g} / \mathrm{mL})$ was also tested in the bioassay. The potassium dichromate reference toxin was rapid in its onset of mortality, inducing nauplii death within $3 \mathrm{hr}$ of exposure, with $100 \%$ mortality evident following 4-5 hr (results not shown). Both the methanolic and aqueous extracts displayed $100 \%$ mortality rates at $24 \mathrm{hr}$. The toxicity of the extracts was further quantified by testing across a range of concentrations and the $\mathrm{LC}_{50}$ was calculated by linear regression. As toxicity in this assay has been defined as an $\mathrm{LC}_{50}<1000 \mu \mathrm{g} / \mathrm{mL}$, both extracts were deemed to be nontoxic. ${ }^{27}$

\section{HPLC-MS analysis}

The A. acidula methanolic and aqueous extracts were analysed by HPLC-MS fingerprinting to identify phytochemical components. The mass signal peaks were analysed by comparison against three accurate mass databases; a database of known plant compounds of therapeutic importance generated specifically for this study (650 compounds); the Metlin metabolomics database $(24,768$ compounds); and the Forensic Toxicology Database by Agilent Technologies (7,509 compounds). As flavonoids and terpenoids have previously been reported to have good antibacterial activity against a broad range of bacteria, these classes of compounds were targeted in this analysis. ${ }^{28}$ Optimised HPLC-MS parameters were previously developed in our group and were used to separate and identify phytoconstituents within the extracts. ${ }^{26}$ The total

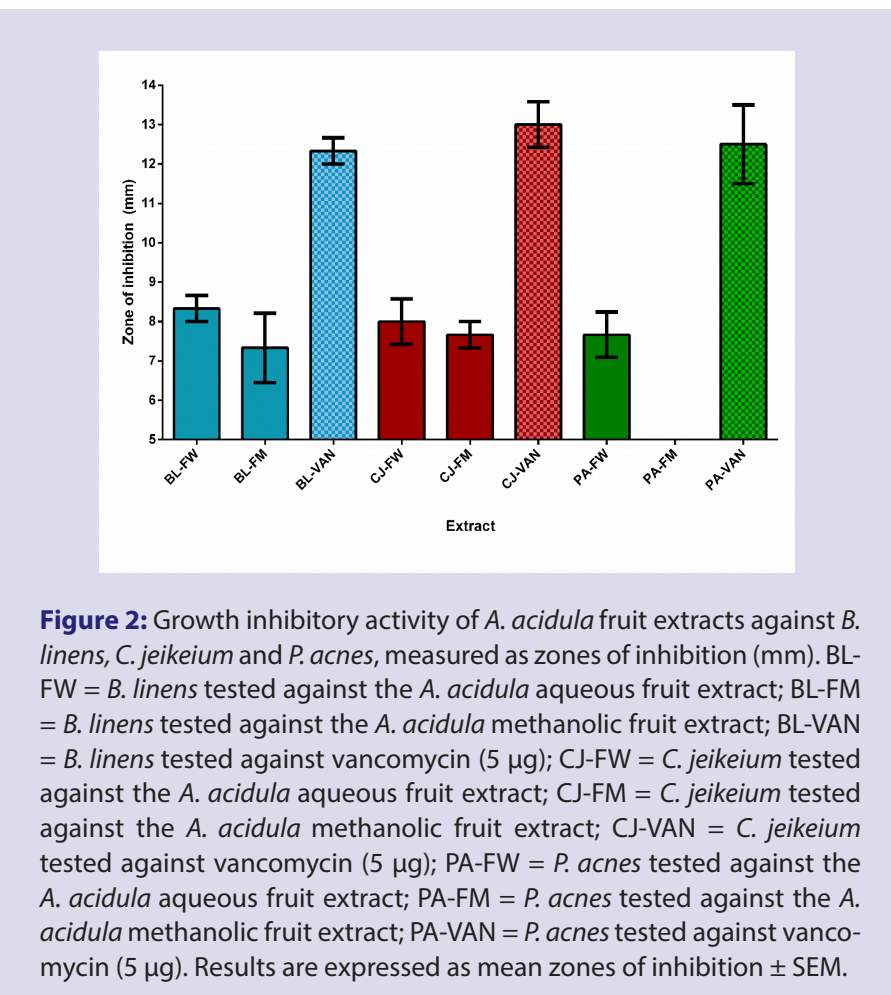


compound chromatograms (TCC) for each extract were recorded in positive ionisation mode and are presented in Figure 4. The methanolic extract chromatogram (Figure $4 \mathrm{a}$ ) had substantially more mass signal peaks (and greater peak intensity) than the aqueous extract (Figure 4b). The flavonoid glycoside rutin was noted in relatively high abundance (as judged by \% total peak area) in both the methanolic and aqueous $A$. acidula fruit chromatograms. The methanolic extract (but not the aqueous extract) also contained a substantial amount of the flavonoid glycoside apiin. The methanolic extract also contained substantial amounts of the sesquiterpenoids calamenene, capsidol, drimene and spathulenol, as well as lower levels of kessyl alcohol. The monoterpenoid cantharidin was also detected in the methanolic extract in abundance. Notably, all of these terpenoid components were absent in the aqueous extract due to the relatively low polarity of these compounds. A number of other peaks were also evident in both chromatograms, particularly in the early and middle stages of the chromatogram corresponding to the elution of polar compounds. Nearly all of the methanol extract compounds had eluted by $17 \mathrm{~min}$ (corresponding to approximately $50 \%$ acetonitrile).

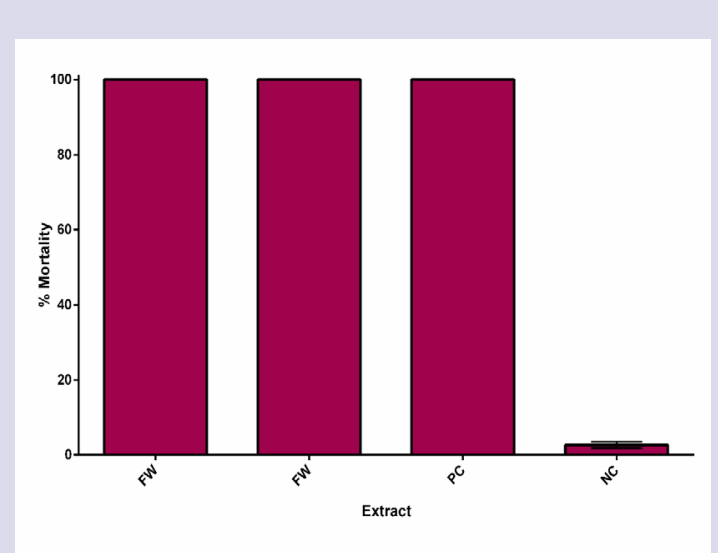

Figure 3: The lethality of the A. acidula extracts $(2000 \mu \mathrm{g} / \mathrm{mL})$ and the potassium dichromate control $(1000 \mu \mathrm{g} / \mathrm{mL})$ towards $A$. franciscana nauplii after $24 \mathrm{hr}$ exposure. $\mathrm{FW}=$ aqueous $A$. acidula fruit extract; $\mathrm{FM}=$ methanolic $A$. acidula fruit extract; $P C=$ potassium dichromate (positive control); NC = artificial seawater control (negative control). Results are expressed as mean $\%$ mortality \pm SEM. Both of the extracts displayed $100 \%$ mortality rates at $24 \mathrm{hr}$.
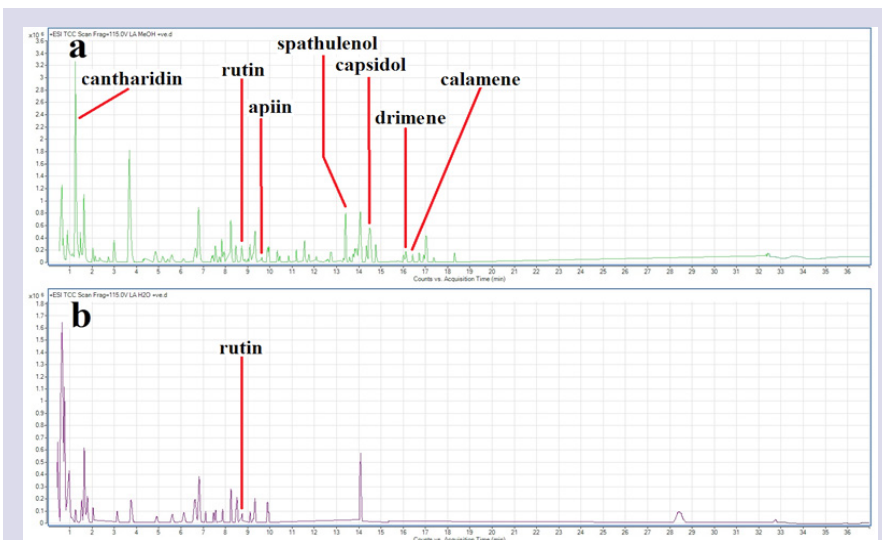

Figure 4: Positive RP-HPLC total compound chromatogram (TCC) of $2 \mu \mathrm{l}$ injections of $A$. acidula (a) methanolic and (b) aqueous extracts run in positive ionisation mode.
Indeed, multiple over lapping peaks eluted in the first 2 min with $5 \%$ acetonitrile. However, the presence of several peaks eluting later in the methanolic extract chromatogram indicate the broad spread of polarities of the compounds in this extract.

\section{DISCUSSION}

Inefficient or incomplete mitigation of axillary/plantar malodour is often a source of embarrassment and can result in lowered self-esteem. Many factors can influence an individual's skin microbiota, including environmental conditions (temperature, humidity) as well as individual circumstances (dietary, medicine intake). Additionally, variances in bacterial distributions are noted where apocrine glands are abundant in axillary and plantar regions, when compared to other regions of the body. ${ }^{1}$ Finally, different clothing types and materials trap varying amounts of heat and this can affect rates of sweat production. Undertaking a wideranging study that accounts for these variables is multifaceted and not within the scope of this study. Instead, we focused on the prevailing malodour-forming bacteria of the axillary and plantar regions. Finally, bacterial waste compounds may also stain clothing and footwear, necessitating their replacement.

Whilst antiperspirants reduce sweat production, these are not formulated to prevent bacterial growth and often perspiration persists irrespective of such preventative measures. Conversely, deodorants are formulated to retard bacterial growth through the incorporation of antimicrobial agents. However, these are typically synthesised chemicals and there are concerns surrounding the effects of prolonged exposure to these compounds and their perceived negative impacts on human health. The utilisation of natural resources to serve as active ingredients in these formulations is advantageous for multiple reasons. From a commercial standpoint, societal concerns surrounding the use of chemicals and the human body can be mitigated through using natural alternatives. Consumers who have a predisposition against chemicals may be less hesitant to adopt products that have been formulated with biological compounds as their active ingredients. Furthermore, the costs associated with chemi-

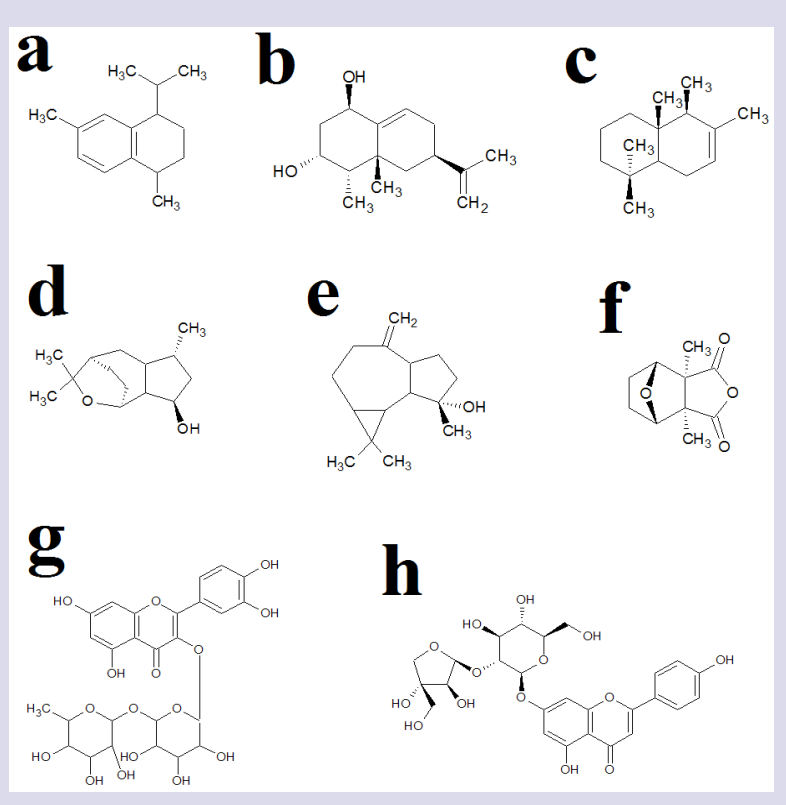

Figure 5: Chemical structures of the compounds identified the methanolic and aqueous A. acidula fruit extracts (a) calamenene; (b) capsidol; (c) drimene; (d) kessyl alcohol; (e) spathulenol acid; (f) cantharidin; (g) rutin; (h) apiin. 
Table 1: The mass of dried extracted material, concentrations after resuspension in deionised water, qualitative phytochemical screenings and antioxidant capacities of the A. acidula fruit extracts.

\begin{tabular}{|c|c|c|c|c|c|c|c|c|c|c|c|c|c|c|c|c|}
\hline 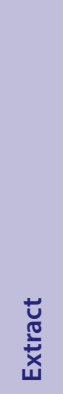 & 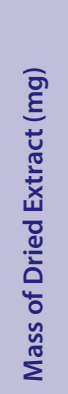 & 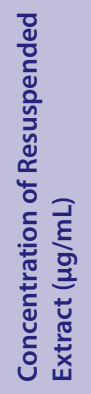 & 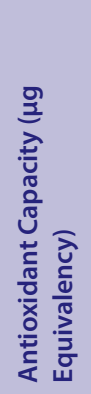 & 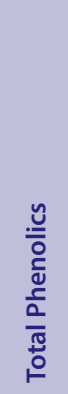 & $\begin{array}{l}\frac{y}{0} \\
\overline{0} \\
\frac{c}{0} \\
\frac{5}{0} \\
\frac{0}{0} \\
\frac{0}{3} \\
\overline{0} \\
\frac{1}{0} \\
\frac{\pi}{3} \\
\frac{\pi}{3}\end{array}$ & 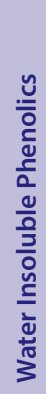 & 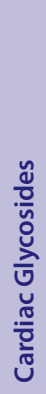 & 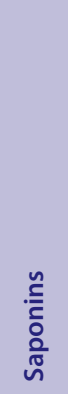 & 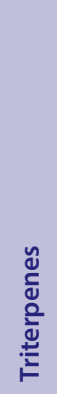 & 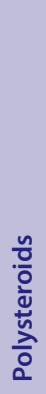 & 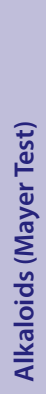 & 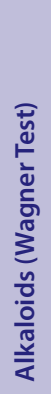 & $\begin{array}{l}\frac{n}{0} \\
0 \\
\frac{0}{0} \\
\frac{\pi}{4} \\
\frac{0}{4}\end{array}$ & 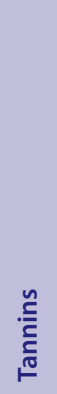 & 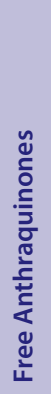 & 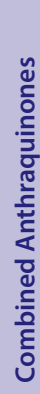 \\
\hline FW & 162 & 16.2 & 7.2 & +++ & - & - & + & +++ & ++ & - & - & - & +++ & - & - & - \\
\hline $\mathrm{FM}$ & 360 & 36 & 15.9 & +++ & - & - & + & - & ++ & - & - & - & +++ & - & - & - \\
\hline
\end{tabular}

$\mathrm{FW}=\mathrm{A}$. acidula aqueous fruit extract; $\mathrm{FM}=\mathrm{A}$. acidula methanolic fruit extract.

Table 2: Minimum inhibitory concentration $(\mu \mathrm{g} / \mathrm{mL})$ of the plant extracts and $\mathrm{LC}_{50}$ values $(\mu \mathrm{g} / \mathrm{mL})$ in the Artemia nauplii bioassay.

\begin{tabular}{cccc}
\hline Extract & Bacterium & MIC & LC $_{50}$ \\
\hline \multirow{2}{*}{ FW } & B. linens & 1258 & 1872 \\
& C. jeikeium & 1630 & 1872 \\
& P. acnes & 1455 & 1872 \\
FM & B. linens & 2608 & 1500 \\
& C. jeikeium & 3044 & 1500 \\
PC & P. acnes & - & 1500 \\
SW & - & $-*$ & $186^{\#}$ \\
\hline
\end{tabular}

$\mathrm{FW}=$ A. acidula aqueous fruit extract; $\mathrm{FM}=$ A. acidula methanolic fruit extract; $\mathrm{SW}=$ seawater control. Numbers indicate the mean $\mathrm{MIC}$ and $\mathrm{LC}_{50}$ values of triplicate determinations. - indicates no inhibition; $\mathrm{PC}=$ positive control; * indicates that standard vancomycin discs were used as the positive control; \# indicates that potassium dichromate was used as the positive control.

cal synthesis could be reduced and instead desired plants can be readily harvested and processed. Therefore, there is a need for cheap and effective new methods of decreasing body malodour production.

The A. acidula extracts examined in this study had comparable (albeit slightly lower) growth inhibitory efficacy against malodour-producing bacteria to the Australia, South African and Indian Terminalia spp. as well as the Syzygium spp. that were tested in our previous studies. ${ }^{4,12,23}$ The results obtained in this study differ somewhat from our earlier research, as in this study, the aqueous extracts were a better inhibitor of bacterial growth than the methanolic counterparts. Moreover, there was no inhibition detected by the methanolic fruit extract against $P$. acnes whatsoever, whereas in previous studies growth inhibition of other methanolic fruit extracts were observed. While comparisons between extracts of different plants cannot be directly drawn, it is interesting that the bioactive compounds in A. acidula that inhibit $P$. acnes growth are specific to the aqueous extract, likely indicating the relative polarity of the bioactive compounds. In particular, rutin was highlighted in these extracts. Interestingly, rutin has been reported to have antibacterial activity against some bacterial pathogens, although it is yet to be tested against the odour-forming bacteria. ${ }^{29-32}$ It is possible that it may contribute to the growth inhibitory properties reported here, although this is yet to be verified.
The phytochemical components responsible for the growth inhibitory activity of the $A$. acidula extracts were not definitively identified in this study. However, metabolomic fingerprint analysis was used to highlight some extract components in the A. acidula extracts that may contribute to that activity. In particular, a diversity and relative abundance of terpenoids were identified within the A. acidula extracts. Sesquiterpenoids were especially prevalent, with calamenene (Figure 5a), capsidol (Figure 5b), drimene (Figure 5c), kessyl alcohol (Figure 5d) and spathulenol (Figure 5e) putatively identified in the methanolic A. acidula extracts. The terpenoid cantharidin (Figure 5f) was also abundant in the methanolic A. acidula extract. Many of these terpenoids have potent broadspectrum antibacterial activity and therefore may contribute to the growth inhibitory activity of the $A$. acidula extracts against the malodour forming bacteria. ${ }^{27}$ The flavonoid glycosides rutin (Figure $5 \mathrm{~g}$ ) and apiin (Figure 5h) were also detected in the A. acidula extracts. Many studies have reported potent antibacterial activities for a wide variety of flavonoids. ${ }^{27}$ Thus, it is likely that multiple compounds within the A. acidula extracts contribute to the growth inhibition of the odour forming bacteria. Future studies are required to quantify the efficacy of these components alone and also to determine whether some components potentiate the activity of other components.

Whilst our studies provide insight into the phytochemical composition of these extracts, it is noteworthy that mass spectral techniques are generally not capable on their own of differentiating between structural isomers. Further studies using a wider variety of techniques are required to confirm the identity of the compounds putatively identified here. It is also likely that other phytochemical classes contribute to the growth inhibitory properties of these extracts. Our qualitative phytochemical screening studies indicate that polyphenolics, flavonoids, saponins and terpenes were present in the A. acidula extracts. As our study used HPLC-MS techniques to putatively identify the phytochemical composition of the extracts, many of the larger and/or lower polarity compounds may have not been identified. Future studies using GC-MS methods are required to analyse the lower polarity and volatile components of the extracts.

\section{CONCLUSION}

The results of this study demonstrate the potential of $A$. acidula fruit extracts as natural antibacterial components for deodorant formulation. The aqueous extract in particular showed significant growth inhibition against all malodour forming bacteria tested. While our study identified multiple compounds with antibacterial activity, further analyses are 
needed to fully elucidate the phytochemistry of the A. acidula extracts ad their mechanistic action/s.

\section{ACKNOWLEDGEMENT}

Financial support for this work was provided by the Environmental Futures Research Institute and the School of Natural Sciences, Griffith University, Australia.

\section{CONFLICT OF INTEREST}

All authors report no conflicts of interest.

\section{ABBREVIATIONS}

DMSO: Dimethyl sulfoxide; $\mathrm{LC}_{50}$ : The concentration required to achieve $50 \%$ mortality; MIC: Minimum inhibitory concentration; ZOI: Zone of inhibition.

\section{REFERENCES}

1. Benohanian A. Antiperspirants and deodorants. Clin Dermatol. 2001;19(4):398 405.

2. Callewaert C, Hutapea P, DeWiele TV, Boon N. Deodorants and antiperspirants affect the axillary bacterial community. Arch Dermatol Res. 2014;306(8):701-10. doi:10.1007/s00403-014-1487-1.

3. Grice EA, Kong HH, Conlan S, et al. Topographical and temporal diversity of the human skin microbiome. Science. 2009;324(5931):1190-2. doi:10.1126/science. 1171700

4. McManus $\mathrm{K}$, Wood $\mathrm{A}$, Wright $\mathrm{MH}$, et al. Terminalia ferdinandiana Exell. ex tracts inhibit the growth of body odour-forming bacteria. Int J Cosmet Sci. 2017;39(5):500-10. doi:10.1111/ics.12403

5. Wright $\mathrm{MH}$, Lee $\mathrm{CJ}$, Pollock $\mathrm{CE}$, et al. Growth inhibitory activity of selected high antioxidant Australian Syzygium species against the food poisoning and tissue necrotic pathogen Clostridium Perfringens. Pharmacogn Commun 2016;6(2):93-9. doi:10.5530/pc.2016.2.7

6. Kanlayavattanakul M, Lourith N. Body malodours and their topical treatment agents. Int J Cosmet Sci. 2011;33(4):298-311. doi:10.1111/j.14682494.2011.00649.x

7. Flarend R. Absorption of Aluminum from Antiperspirants and Vaccine Adjuvants Aluminium and Alzheimer's Disease: The Science that Describes the Link: Elsevier. Amsterdam. 2001;75-96. doi:10.1016/B978-044450811-9/50029-X

8. Bhargava HN, Leonard PA. Triclosan: Applications and safety. Am J Infect Control. 1996;24(3):209-18. doi:10.1016/S0196-6553(96)90017-6

9. Australian Tropical Rainforest Plants. Acronychia acidula. 2020. <http://keys.trin. org.au:8080/key-server/data/0e0f0504-0103-430d-8004-060d07080d04/media/ $\mathrm{Html} /$ taxon/Acronychia_acidula.htm>

10. Rural Industries. Focus on A. acidula. 2020. < https://www.agrifutures.com.au/ wp-content/uploads/publications/14-116.pdf>

11. Sultanbawa $Y$, Sultanbawa F. Australian Native Plants: Cultivation and Uses in the Health and Food Industries. CRC Press, Boca Raton. 2016;376. ISBN: 9781315372389. doi:10.1201/b20635

12. Cock IE, Wright MH, Matthews B, et al. Bioactive compounds sourced from Terminalia spp. in bacterial malodour prevention: An effective alternative to chemical additives. Int J Cosmet Sci. 2019;41(5):496-508. doi:10.1111/ics.12567

13. Cock IE, Maen A. Inhibitory activity of high antioxidant Australian native fruits against the bacterial triggers of selected autoimmune diseases. Pharmacog Commn. 2015;5(1):48-59.
14. Lee CJ, Wright MH, Greene AC, et al. Preliminary evaluations of the antibacterial activity of Tasmannia lanceolata against Bacillus anthracis: Natural resource probing to prevent anthrax. Pharmcog Commn. 2019;9(4):124-9. doi:10.5530/ pc.2019.4.26

15. Wright $\mathrm{MH}$, Arnold MSJ, Aldosary $\mathrm{H}$, et al. Bioactive constituents of Terminalia ferdinandiana Exell: A pharmacognistic approach towards the prevention and treatment of yersiniosis. Pharmacogn Commn. 2016;6(3):152-63. doi:10.5530/ pc.2016.3.5

16. Wright MH, Greene AC, Cock IE. Inhibition of Bacillus anthracis growth by Australian native plants used traditionally as antibacterial medicines. Pharmacogn J. 2015;7(6):389-96. doi:10.5530/pj.2015.6.13

17. Mitchell HW, Joseph S, Ben M, Tony G. Growth inhibitory activity of Kakadu Plum extracts against the opportunistic pathogen Clostridium perfringens: New leads in the prevention and treatment of clostridial myonecrosis. Pharmacogn J. 2016;8(2):144-53. doi:10.5530/pj.2016.2.8

18. Wright MH, Sirdaarta J, White A, et al. GC-MS headspace analysis of Terminalia ferdinandiana fruit and leaf extracts which inhibit Bacillus anthracis growth. Pharmacogn J. 2016;9(1):73-82. doi:10.5530/pj.2017.1.14

19. Wright MH, Shalom J, Matthews B, et al. Terminalia ferdinandiana Exell: Extracts inhibit Shewanella spp. growth and prevent fish spoilage. Food Microbiol. 2019;78:114-22. doi:10.1016/j.fm.2018.10.006

20. Murhekar S, Wright MH, Greene AC, et al. Inhibition of Shewanella spp. growth by Syzygium australe and Syzygium luehmannii extracts: Natural methods for the prevention of fish spoilage. J Food Sci Technol. 2017:54(10):3314-26. doi:10.1007/s13197-017-2782-6

21. Wright $\mathrm{MH}$, Adelskov J, Greene AC. Bacterial DNA extraction using individual enzymes and phenol/chloroform separation. J Microbiol Biol Educ. 2017;18(2):13. doi:10.1128/jmbe.v18i2.1348

22. Farooqui SM, Wright MH, Greene AC. Aliidiomarina minuta sp. nov., a haloalkaliphilic bacterium that forms ultra-small cells under non-optimal conditions. Antonie van Leeuwenhoek. 2016;109(1):83-93. doi:10.1007/s10482-015-0611-3

23. Wright $\mathrm{MH}$, Matthews $\mathrm{B}$, Arnold MSJ, et al. The prevention of fish spoilage by high antioxidant Australian culinary plants: Shewanella putrefaciens growth inhibition. Int J Food Sci Technol. 2016;51(3):801-13. doi:10.1111/ijfs.13026

24. Cock IE, Ruebhart DR. Comparison of the brine shrimp nauplii bioassay and the ToxScreen-II test for the detection of toxicity associated with Aloe vera (Aloe barbadensis Miller) leaf extract. Pharmacogn Res. 2009;1(2):98-101.

25. Wood AJ, McManus K, Wright MH, et al. Growth inhibitory activity of selected Australian Syzygium species against malodour forming bacteria. Pharmacogn Commun. 2017;7(3):129-36. doi: 10.5530/pc.2017.3.19

26. Rayan $P$, Matthews $B$, McDonnell A, et al. Terminalia ferdinandiana extracts as inhibitors of Giardia duodenalis proliferation: A new treatment for giardiasis. Parasitol Res. 2015;114(7):2611-20. doi:10.1007/s00436-015-4465-4

27. Sirdaarta J, Cock, IE. Vitamin E and Trolox TM reduce toxicity of Aloe barbadensis Miller juice in Artemia franciscana nauplii but individually are toxic at high concentrations. Int J Toxicol. 2008;5(1):1-9.

28. Cock IE. The phytochemistry and chemotherapeutic potential of Tasmannia lanceolata (Tasmanian pepper): A review. Pharmacog Commn. 2013;3(4):13-25

29. Dubey S, Ganeshpurkar A, Bansal D, et al. Experimental studies on bioactive potential of rutin. Chron Young Sci. 2013;4(2):153-7.

30. Arima H, Ashida H, Danno GI. Rutin-enhanced antibacterial activities of flavonoids against Bacillus cereus and Salmonella enteritidis. Biosci Biotechnol Biochem. 2002;66(5):1009-14.

31. Pimentel RB, DaCosta CA, Albuquerque PM, et al. Antimicrobial activity and rutin identification of honey produced by the stingless bee Melipona compressipes manaosensis and commercial honey. BMC Complement Altern Med. 2013;13(1):151.

32. Araruna MK, Brito SA Morais-Braga MF et al Evaluation of antibiotic and antibiotic modifying activity of pilocarpine and rutin. Indian J Med Res. 2012;135(2):252-4. 


\section{PICTORIAL ABSTRACT}

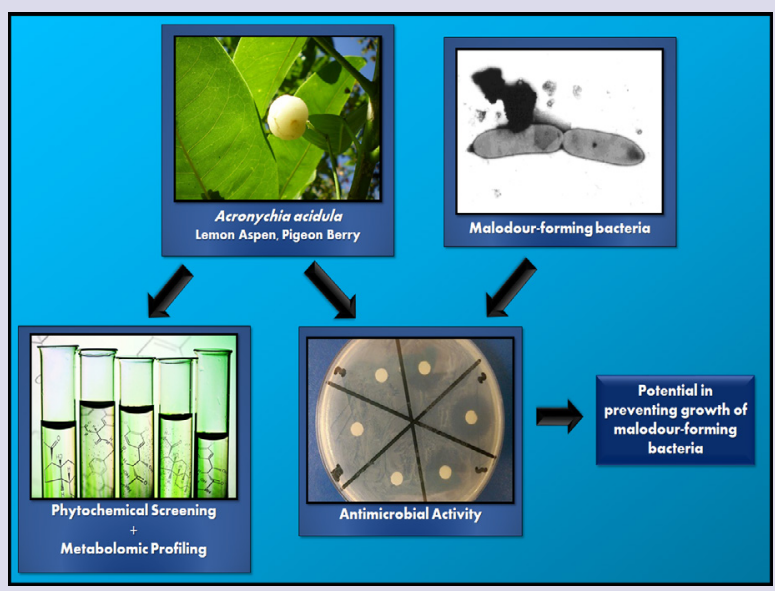

\section{SUMMARY}

- A. acidula fruit extracts were screened for the ability to block the growth of body odour forming bacteria.

- The antibacterial activity was quantified by determining the MIC values of each extract.

- $\quad$ LC-MS metabolomics fingerprint analysis was used to identify several phytochemical compounds with known antibacterial activity.

- $\quad$ Toxicity of the A. acidula fruit extracts was determined using the Artemia nauplii toxicity bioassay.

\section{ABOUT AUTHORS}
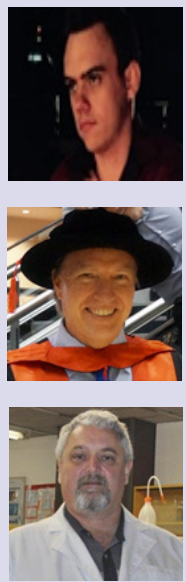

Dr. Mitchell Henry Wright is a Geomicrobiologist who received his Ph.D. in 2014 for his work investigating the manganese reduction/ oxidation characteristics of environmental bacteria. From 2016 to 2018 he undertook a postdoctoral researcher role under the mentorship of Prof. Bradley Tebo, where he explored the bacterial oxidative formation and removal of complexed Mn(III) and the implications of these processes on the global ocean. Upon returning to Australia, Dr. Mitchell H. Wright was recruited by First Choice College and to date, oversees their Department of Research and Development.

Dr. Anthony Carlson Greene is a senior lecturer and researcher at Griffith University, Brisbane Australia. He obtained his PhD in Microbiology from the University of New South Wales and focuses on extreme environments, bioremediation and geomicrobiology. His specific interests include the microbial ecology of thermophilic, saline and alkaliphilic environments and the mechanisms and industrial potential of extremophilic bacteria contained therein.

Dr. Ian Cock leads a research team in the Environmental Futures Research Institute and the School of Natural Sciences at Griffith University, Australia. His research involves bioactivity and phytochemical studies into a variety of plant species of both Australian and international origin, including Aloe vera, South Asian and South American tropical fruits, as well as Australia plants including Scaevola spinescens, Pittosporum phylliraeoides, Terminalia ferdinandiana (Kakadu plum), Australian Acacias, Syzygiums, Petalostigmas and Xanthorrhoea johnsonii (grass trees). This range of projects has resulted in over 150 publications across a variety of peer reviewed journals. 